\title{
Partisipasi Masyarakat Dalam Perencanaan Pembangunan (Musrembang) DI Kelurahan Kadidi Kecamatan Panca Rijang Kabupaten Sidenreng Rappang
}

\author{
Rina Angreni \\ Porodi Administrasi Publik. Fakultas Ilmu Sosial dan Ilmu Politik \\ Universitas Muhammadiyah Sidenreng Rappang \\ Email : rinaangreni0809@gamil.com
}

\begin{abstract}
ABSTRAK
Tujuan penelian untuk mengetahui partisipasi masyarakat dalam perencanaan pembangunan (musrembang) di Kelurahan Kadidi. Partisipasi masyarakat di kelurahan dalam penyusunan rencana pembangunan kelurahan Di Kadidi dapat menjadi salah satu tolak ukur sejauh mana kelurahan tersebut mengembangkan nilai-nilai tata kelola pemerintahan kelurahan yang baik dalam roda pemerintahannya. Keterlibatan masyarakat kelurahan dalam arti luas harus didorong baik melalui regulasi maupun penciptaan iklim demokratisasi yang ideal di kelurahan. Partisipasi dalam konteks pelaksanaan Musyawarah Perencanaan Pembangunan (Musrembang) kekurahan, ternyata lebih dipahami sebagai kontribusi masyarakat kelurahan untuk meningkatkan efektivitas dan efisiensi pembangunan. Bukan secara komprehensif untuk mempromosikan demokratisasi dan pemberdayaan masyarakat kelurahan dalam pengambilan keputusan pembiayaan pembangunan, sehingga pemerintah kelurahan dan BPD belum bisa menjamin bahwa seluruh usul masyarakat dalam Musrenbang akan direalisasika. Dengan Musrenbang ini, rakyat banyak diharapkan bisa berpartisipasi dalam proses pembangunan. Pemerintah menginginkan agar proses pembangunan digagas dari bawah. Ada beberapa persoalan yang menyebabkan Musrenbang tidak efektif. Pertama, prinsip partisipasi rakyat dalam proses Musrenbang sangat minim. Kedua, prinsip responsive, Musrenbang kurang ditopang oleh pembangunan organisasi- organisasi rakyat. Demokrasi tidak mungkin berdiri tanpa adanya rakyat yang terorganisir. Ketiga, prinsip holistic, proposal Musrenbang sering disabotase oleh birokrasi korup peninggalan kolonialisme. Dalam banyak kasus, proposal Musrenbang dari kelurahan tidak diwakili oleh delegasi yang ditunjuk rakyat. Akan tetapi, pada tingkat kelurahan, forum Musrenbang berpotensi dimajukan oleh gerakan rakyat. Asalkan bisa membangkitkan partisipasi rakyat di dalamnya, maka forum Musrenbang di tingkat lokal bisa menjadi alat untuk memaksa pemerintahan lokal merespon kebutuhankebutuhan mendesak rakyat.
\end{abstract}

Kata Kunci : Partisipasi Masyarakat; Musrenbang

\begin{abstract}
The purpose of the study was to determine community participation in development planning (musrembang) in Kadidi Village. Community participation in the kelurahan in the preparation of kelurahan development plans At Kadidi can be one of the benchmarks for the extent to
\end{abstract}


which the kelurahan develops the values of good kelurahan governance in its governance. The involvement of the urban village community in a broad sense must be encouraged both through regulations and the creation of an ideal democratizing climate in the village. Participation in the context of the implementation of the Village Development Planning Deliberation (Musrembang) is more understood as the contribution of the village community to improve the effectiveness and efficiency of development Not comprehensively to promote democratization and empowerment of urban village communities in making decisions on development financing, so that the village government and BPD cannot guarantee that all community proposals in the Musrenbang will be realized. With this Musrenbang, many people are expected to participate in the development process. The government wants the development process to be initiated from below. There are several problems that make Musrenbang ineffective. First, the principle of people's participation in the Musrenbang process is minimal. Second, the responsive principle, Musrenbang is not supported by the development of people's organizations. Democracy cannot exist without an organized people. Third, the holistic principle, Musrenbang proposals are often sabotaged by the corrupt bureaucracy left by colonialism. In many cases, the Musrenbang proposals from the kelurahan are not represented by delegates appointed by the people. However, at the kelurahan level, the Musrenbang forum has the potential to be promoted by the people's movement. As long as it can generate people's participation in it, then the Musrenbang forum at the local level can be a tool to force the local government to respond to the people's urgent needs.

\section{Keywords: Community Participation; Musrenbang}

\section{PENDAHULUAN}

Musyawarah Perencanaan dan Pembangunan (Musrenbang) pada hakikatnya adalah forum perencanaan pembangunan formal yang berusaha mempertemukan aspirasi masyarakat dari bawah dengan usulan program pembangunan dari instansi pemerintah. Musrenbang tercantum dalam beberapa undang-undang dan perda terkait dengan perencanaan pembangunan daerah. Musrenbang merupakan wahana publik yang penting untuk membawa para pemangku kepentingan memahami isu-isu dan permasalahan-permasalahan untuk mencapai kesepakatan atas prioritas pembangunan, dan konsesus untuk pemecahan berbagai masalah pembangunan. Musrenbang juga merupakan wahana untuk mensinkronisasikan pendekatan "top Down" dengan "bottom up" pendekatan penilaian kebutuhan masyarakat dengan penilaian yang bersifat teknis, resolusi konflik atas berbagai kepentingan pemerintah dan diluar pemerintah untuk pembangunan daerah, antara kebutuhan program pembangunan dengan kemampuan dan kendala pendanaan, dan wahana untuk mensinergikan berbagai sumber pendanaan pembangunan(Salangka, 2004).

Partisipasi masyarakat dapat diartikan sebagai bentuk keterlibatan masyarakat yang memiliki tujuan dan kebutuhan yang sama dalam pengambilan keputusan yang mempengaruhi kehidupannya. Pengertian partisipasi sendiri sangat beragam. Dalam konteks ini, partisipasi di artikan sebagai keterlibatan masyarakat secara aktif dalam setiap tahapan pembangunan mulai dari perencanaan hingga pelaksanaan. Masyarakat tidak lagi menjadi objek dari pembangunan tetapi menjadi subjek pembangunan, dimana masyarakat berperan dalam menyampaikan aspirasi, menentukan pilihan, memanfaatkan peluang dan menyelesaikan masalahnya(Mustanir, Dema, Syarifuddin, Meity, \& Wulandari, 2018). 
Pembangunan kelurahan merupakan bagian integral dari pembangunan nasional mempunyai arti yang strategis, sehingga berhasilnya pembangunan akan menyentuh seluruh lapisan masyarakat dan memungkinkan peningkatan pemerataan pembangunan dan hasilhasilnya menuju tercapainya masyarakat adil dan makmur merata material dan spiritual(A. Mustanir and Razak 2017) (Ahmad Mustanir et al. 2018) (A. Mustanir, n.d.)(Mustanir et al., 2018).

Dalam upaya pembangunan diperlukan adanya bentuk partisipasi masyarakat mulai dari proses perencanaannya sampai pada proses pelaksanaannya, sehingga pembangunan desa tersebut menyentuh segala kebutuhan masyarakatnya. Kadangkala pembangunan desa itu terhambat akibat masalah yang ditimbulkan oleh partisipasi masyarakat desa tersebut. Masyarakat(Mustanir et al., 2018).

Musrenbang merupakan wahana untuk mensinkronisasikan pendekatan "top down" dengan "bottom up" pendekatan penilaian kebutuhan masyarakat dengan penilaian yang bersifat teknis. Musrenbang adalah wahana publik yang penting untuk membawa stakeholder memahami isu isu dan permasalahan daerah mencapai kesepakatan atas prioritas pembangunan, dan konsesus untuk pemecahan berbagai masalah pembangunan daerah(P. A. Ahmad Mustanir, 2017).

Musrenbang dilaksanakan baik pada tingkat desa/kelurahan, kecamatan, maupun tingkat kabupaten. Walaupun selama ini hasil dari forum tersebut di beberapa daerah tidak bisa dimplementasikan dan formalitas saja. Pendekatan partisipatif dalam perencanaan melalui mekanisme musrenbang masih cenderung menjadi retorika. Perencanaan pembangunan didominasi oleh kebijakan kepala daerah, hasil reses DPRD dan program SKPD. Kondisi ini berakibat timbulnya akumulasi kekecewaan di tingkat kelurahan dan kecamatan yang sudah memenuhi kewajiban membuat rencana tapi realisasi sangat minim(P. A. Ahmad Mustanir, 2017).

\section{TINJAUAN PUSTAKA}

\section{- Teori Partisipasi Masyarakat}

Partispasi masyarakat merupakan suatu proses yangdapat mendukung masyarakat untuk mulai "sadar" akan situasi dan masalah yang dihadapinya serta berupaya mencari jalan keluar yangdapat dipakai untuk mengatasi masalah mereka (memiliki kesadaran kritis). Sumardi (2010:46), mengemukakan bahwa partisipasi adlah peran serta seseorang atau kelompok masyarakat dalam proses pembangunan baik dalam bentuk pernyataan maupun dalam bentuk kegiatan dengan memberi masukan pikiran, tenaga, waktu, keahlian, modal, dan atau materi, serta ikut memanfaatkan dan menikmati hasil-hasil pembangunan. (Zhilviana Sulaeman, Ahmad Mustanir, 2019).

Mubyartoadalah:

(D. Ahmad Mustanir, 2016) Indikator Partisipasi Masyarakat menurut

a. Terlibat memikul tanggung jawab pelaksanaan pembangunan

b. Musyawarah perencanaan pembangunan

c. Pelaksana hasil perencanaan pembangunan

d. Kesediaan membayar iuran sebagai dana swadaya

e. Kesediaan masyarakat dalam menyumbang material seperti pasir, batu bata, semen. 
Warsito (2007:25) mendefenisikan: partisipasi merupakan kesediaan untuk membantu berhasilnya setiap program sesuai dengan kemampuan setiap orang tanpa berarti mengorbankan kepentingan diri sendiri. Sinaga (2005:61) menyebutkan partisipasi antara sesama warga atau anggota suatu perkumpulan dengan partisipasi horizontal, dan partisipasi yang dilakukan oleh bawahan dengan atasan, antar klien dengan patron, atau antara masyarakat sebagai keseluruhan pemerintah, dengan partisipasi vertikal. Keterlibatan dalam berbagai kegiatan politik seperti pemberian suara dalam pemilihan, kampanye dan lain sebagainya, disebut partisipasi dalam proses politik, sedangkan keterlibatan dalam kegiatan seperti perencanaan dan pelaksanaan pembangunan disebut partisipasi dalam proses administratif. Sementara itu keterlibatan masyarakat sebagai suatu kesatuan disebut dengan partisipasi kolektif, sedangkan keterlibatan individual dalam kegiatan kelompok disebut partisipasi individual. Partisipasi vertikal terjadi dalam kondisi tertentu masyarakat yang terlibat atau yang mengambil bagian dalam suatu program dengan pihak lain. Dalam hubungan dimana masyarakat berada pada posisi sebagai bawahan, pengikut atau klien. Partisipasi horizontal antara satu dengan yang lain, baik dalam melakukan usaha bersama, maupun dalam rangka melakukan kegiatan dengan pihak lain. Jika masyarakat desa yang bersangkutan tidak berkesempatan berpartisipasi dalam pembangunan suatu proyek di desanya, proyek tersebut pada hakikatnya bukanlah proyek pembangunan kelurahan.

Partisipasi Masyarakat. Didalam melaksakanan suatu program atau pun suatu badan usaha sangat dibutuhkan pasrtisipasi masyarakat didalam nya agar semua program yang telah di rencakan oleh suatu organisasi bisa berjalan sebagaimana mestinya, selain partisipsi kondisi masyarakat juga sangat berpengaruh didalam keberhasilan program yang telah di rencanakan(Mustanir \& Adnan, 2020).

\section{- Musyawarah Perencanaan Pembangunan ( Musrembang )}

Musyawarah perencanaan pembangunan merupakan forum perencanaan (program) yang diselenggarakan oleh lembaga publik yaitu pemerintah desa bekerjasama dengan warga dan para pemangku kepentingan lainnya. Musyawarah perencanaan pembangunan yang menurut Sumpeno (2008:28) merupakan perencanaan pembangunan bersama masyarakat adalah merupakan panduan atau model pembangunan desa yang menitikberatkan pada peran serta masyarakat dalam keseluruhan proses pembangunan(Mustanir \& Yasin, 2018).

Di Kelurahan Kadidi merupakan salah satu bentuk pemerintahan kelurahan yang berada dalam wilayah Kecamatan Panca Rijang Kabupaten Sidenreng Rappang yang secara umum peranan aparatur desa dan partisipasi masyarakat masih terlihat kurang baik, padahal pelaksanaan musrenbang masyarakat menjadi penentu bagi keberhasilannya. Tantangan yang dihadapi oleh aparatur pemerintah desa yang sesuai dengan kondisi masyarakatnya sangat tergantung pada upaya-upaya peningkatan partisipasi masyarakat yang saat ini masih kurang.

Pembangunan nasional dan daerah merupakan bagian yang tidak dapat dipisahkan dari kegiatan pembangunan desa. Desa merupakan basis kekuatan social ekonomi dan politik yang perlu mendapat perhatian serius dari pemerintah. Perencanaan pembangunan selama ini menjadikan masyarakat desa sebagai obyek pembangunan bukan sebagai subyek pembangunan(Ahmad Mustanir1), Kamaruddin Sellang2), Akhwan Ali3), Madaling4) \& 1), 2018).

\section{METODE PENELITIAN}


Penelitian ini menggunakan metode deskriptif kualitatif. (Moleong, 2010 : 3) Teknik pengumpulan data yang dilakukan adalah : melalui Penelitian Lapangan dengan cara observasi dan wawancara (Data Primer), Studi keputusan/library research (membaca buku, majalah surat kabar, dokumen-dokumen, dan mediainformasi lain dan Penerusan data online yakni menggunakan fasilitas internet (Data Sekunder). Untuk mendapatkan hasil yang objektif dalam penelitian ini, maka data yang didapatkan dilapangan akan diolah dan dianalisisa secara kualitatif, yaitu dengan menggambarkan dan menjelaskan hasil-hasil penelitian dari sejumlah data-data yang telah diperoleh.

\section{PEMBAHASAN}

Musrenbang desa adalah adanya musyawarah dalam merumuskan rencana pembangunan desa. Konsep musyawarah menunjukkan bahwa forum Musrenbang desa bersifat partisipatif dan dialogis, bukan seminar dan sosialisasi informasi. Proses musrenbang desa jangan sampai disusun sebagai suatu acara seremonial yang separuh atau sebagian besar dari waktunya diisi dengan sambutan dan pidato-pidato. Inti dari musrenbang desa adalah partisipasi aktif warga. Dalam Musrembang, pelibatan masyarakat merupakan cerminan dari praktik partisipasi warga dan sekaligus arena akuntabilitas pemerintahan kelurahan. Keberhasilan Pemerintahan dalam suatu kelurahan sudah tentu disebabkan oleh berbagai faktor berdasarkan teori Ilmu Pemerintahan, salah satu diantaranya adalah personalisasi Kepala Kelurahan atau disebut saja Lurah. Sebagai pemimpin pemerintahan ditingkat kelurahan, para lurah tidak hanya dituntut untuk mampu mengatur pekerjaan administrasi pemerintahan di lingkungan kantor kelurahan dalam rangka memberikan pelayanan maksimal kepada masyarakat, tapi sangat diharapkan berkemampuan mengatur berbagai aspek hidup masyarakatnya terutama dalam mewujudkan keamanan dan ketertiban(Andi Damis Dadda, Ahmad Mustanir, Andi Nilwana, 2018).

Anoraga (2003 : 120) mengartikan kepemimpinan sebagai proses memberikan inspirasi kepada semua karyawan untuk bekerja sebaik-baiknya agar dapar mencapai hasil yang diharapkan. Kepemimpinan juga merupakan dimensi utama yang sangat menentukan kinerja organisasi. Dimana esensi pokok kepemimpinan yaitu upaya mempengaruhi orang agar dapat lebih efektif, disebabkan dalam kepemimpinannya bisa berbeda tergantung karakter, karakteristik tugas dan siapa yang dipimpinnya(Adam Latif 1, Irwan2, 2019).

Ada beberapa kelompok atau organisasi kemasyarakatan yang telah terbentuk di mana anggota- anggota dari organisasi tersebut dipilih melalui musyawarah. Tetapi ada masyarakat yang menilai bahwa kemampuan mereka ternyata masih kurang dalam hal memberdayakan atau menggerakkan segala potensi yang dimiliki oleh masyarakat(Ahmad Mustanir 1) \& Samad 2), Abdul Jabbar 3), Monalisa Ibrahim 4), 2019).

Musrenbang adalah sebuah mekanisme perencanaan, sebuah institusi perencana yang ada di daerah dan sebagai mekanisme untuk mempertemukan usulan/kebutuhan masyarakat (bottom up planning) dengan apa yang akan diprogram pemerintah (tp down planning)(A. Mustanir 2018b) (A. Mustanir 2017). Musrenbang.

Pelaksanaan Musrenbang yang berjenjang mulai dari tingkat desa/kelurahan, kecematan, kabupaten/kota, propinsi, hingga dibawa ke tingkat nasional merupakan kesempatan emas bagi masyarakat untuk dapat terlibat perencanaan pembangunan. Akan tetapi dalam penyelenggaraannya kerap kurang memperhatikan aspek partisipasi secara luas, dan masih terbatas pada seremonial dan acara rutin belaka. Peran lembaga daerah dalam hal 
ini pemerintah daerah dan dewan Perwakilan Rakyat Daerah (DPRD) untuk meningkatkan partisipasi masyarakat khususnya dalam forum Musrenbang mutlak diperlukan sebagai salah satu usaha menuju pemerintahan daerah yang lebih baik (Akhmad, Mustanir, and Ramadhan 2018) (Damis Dadda et al. 2019) (Ahmad Mustanir1), Kamaruddin Sellang2), Akhwan Ali3), Madaling4) \& 1), 2018).

Menurut Conyers dalam (A. Mustanir and Lubis 2017), mengemukakan bahwa ada tiga alasan utama mengapa partisipasi masyarakat sangat penting yaitu : 1). Partisipasi masyarakat merupakan suatu alat guna memperoleh informasi mengenai kondisi, kebutuhan dan sikap masyarakat setempat. 2). Masyarakat akan lebih percaya proyek atau program pembangunan jika merasa dilibatkan dalam proses persiapan dan perencanannya.

Partisipasi anggota masyarakat merupakan keterlibatan anggota masyarakat dalam pembangunan, meliputi kegiatan dalam perencanaan dan pelaksanaan (implementasi) program/proyek pembangunan yang dikerjakan di dalam masyarakat 2 . Sedangkan Partisipasi masyarakat dalam pembangunan diartikan ikut sertanya masyarakat dalam pembangunan, ikut dalam kegiatan pembangunan dan ikut serta pemanfaatan dan menikmati hasil pembangunan(P. A. Ahmad Mustanir, 2017)

\section{KESIMPULAN}

Partispasi masyarakat merupakan suatu proses yangdapat mendukung masyarakat untuk mulai "sadar" akan situasi dan masalah yang dihadapinya serta berupaya mencari jalan keluar yangdapat dipakai untuk mengatasi masalah mereka (memiliki kesadaran kritis). Sumardi (2010:46), mengemukakan bahwa partisipasi adlah peran serta seseorang atau kelompok masyarakat dalam proses pembangunan baik dalam bentuk pernyataan maupun dalam bentuk kegiatan dengan memberi masukan pikiran, tenaga, waktu, keahlian, modal, dan atau materi, serta ikut memanfaatkan dan menikmati hasil-hasil pembangunan.

Musrenbang adalah sebuah mekanisme perencanaan, sebuah institusi perencana yang ada di daerah dan sebagai mekanisme untuk mempertemukan usulan/kebutuhan masyarakat (bottom up planning) dengan apa yang akan diprogram pemerintah (tp down planning).

Menurut Conyers dalam (A. Mustanir and Lubis 2017), mengemukakan bahwa ada tiga alasan utama mengapa partisipasi masyarakat sangat penting yaitu : 1). Partisipasi masyarakat merupakan suatu alat guna memperoleh informasi mengenai kondisi, kebutuhan dan sikap masyarakat setempat. 2). Masyarakat akan lebih percaya proyek atau program pembangunan jika merasa dilibatkan dalam proses persiapan dan perencanannya.

\section{DAFTAR PUSTAKA}

Adam Latif 1, Irwan2, A. M. (2019). Analisis Kepemimpinan Terhadap Optimalisasi Masyarakat Pada Perencanaan Pembangunan Di Enrekang. Journal Homepage, 5(2), 120. https://doi.org/10.20956/xxxxx

Ahmad Mustanir 1), Z., \& Samad 2), Abdul Jabbar 3), Monalisa Ibrahim 4), J. 5. (2019). KEPEMIMPINAN LURAH TERHADAP PEMBERDAYAAN MASYARAKAT DI KELURAHAN LAUTANG BENTENG KABUPATEN SIDENRENG RAPPANG. 
Journal of Social Politics and Governance, 1(2), 20-39.

Ahmad Mustanir, D. (2016). Implementasi kebijakan dana desa dan partisipasi masyarakat dalam pembangunan di desa teteaji kecamatan tellu limpoe kabupaten sidenreng rappang. Jurnal Politik Profetik, 04(2), 226-238.

Ahmad Mustanir, P. A. (2017). Partisipasi masyarakat dalam musyawarah rencana pembangunan di kelurahan kanyuara kecamatan watang sidenreng kabupaten sidenreng rappang. Jurnal Politik Profetik, 5(2), 248-261.

Ahmad Mustanir1), Kamaruddin Sellang2), Akhwan Ali3), Madaling4), M., \& 1). (2018). PERANAN APARATUR PEMERINTAH DESA DAN PARTISIPASI MASYARAKAT DALAM MUSYAWARAH PERENCANAAN PEMBANGUNAN DI DESA TONRONGNGE KECAMATAN BARANTI KABUPATEN SIDENRENG RAPPANG. Jurnal Ilmiah Clean Government, 2(1), 67-84.

Andi Damis Dadda, Ahmad Mustanir, Andi Nilwana, J. (2018). Pengaruh Kepemimpinan Lurah PerempuanTerhadap Stabilitas kamtibmas Di kelurahan Rappang Kabupaten Sidenreng Rappang. 1 Prosiding Konferensi Nasional Ke-, 8(Desember), 1-6.

Mustanir, A., \& Adnan, A. A. (2020). PENGARUH MANAJEMEN PENGELOLAAN BADAN USAHA MILIK DESA TERHADAP PENINGKATAN PARTISIPASI MASYARAKAT DI DESA BILA RIASE KECAMATAN PITU RIASE KEBUPATEN SIDENRENG RAPPANG. Movere Journal, 2(2), 56-65.

Mustanir, A., Dema, H., Syarifuddin, H., Meity, K., \& Wulandari, S. (2018). Pengaruh Motivasi dan Partisipasi Masyarakat terhadap Pembangunan di Kelurahan Lalebata Kecamatan Panca Rijang Kabupaten Sidenreng Rappang. Jurnal Ilmiah Clean Government (JCG), 2(1), 27-39. Retrieved from http://lonsuit.unismuhluwuk.ac.id/index.php/clean/article/view/212

Mustanir, A., \& Yasin, A. (2018). Transect Pada Perencanaan Pembangunan Partisipatif. Jurnal Ilmiah Ilmu Administrasi Publik, 8(2), 21-31.

Salangka, W. P. R. (2004). Partisipasi masyarakat dalam musrenbang di desa malola kecamatan kumelembuai kabupaten minahasa selatan.

Zhilviana Sulaeman, Ahmad Mustanir, A. I. M. (2019). Partisipasi masyarakat terhadap perwujudan good governance di desa damai kecamatan watang sidenreng kabupaten sidenreng rappang. Praja, 7(3), 88-92. 